\title{
Fixed point theorems for generalized JS-quasi-contractions in complete partial b-metric spaces
}

\author{
Panisa Lohawech, Anchalee Kaewcharoen* \\ Department of Mathematics, Faculty of Science, Naresuan University, Phitsanulok 65000, Thailand.
}

\begin{abstract}
In this paper, we introduce a concept of generalized JS-quasi-contractions and obtain sufficient conditions for the existence of fixed points of such mappings on $p_{b}$-complete partial b-metric spaces. Our results extend the results in the literature. In addition, an example is given to illustrate and support our main result.
\end{abstract}

Keywords: Fixed point theorems, partial b-metric spaces, generalized JS-quasi-contractions.

2010 MSC: 47H10, 54H25.

(C)2019 All rights reserved.

\section{Introduction and preliminaries}

A popular tool in nonlinear analysis is the fixed point theory. The Banach contraction principle [2] is the first important result on fixed points for contractive-type mappings. This principle states that, if $(X, d)$ is a complete metric space and $T: X \rightarrow X$ is a Banach contraction (i.e., there exists $k \in[0,1)$ such that $d(T x, T y) \leqslant k d(x, y)$ for all $x, y \in X)$, then $T$ has a unique fixed point. According to its importance and simplicity, there are a lot of generalizations of Banach contraction principle and metric spaces. Wardowski [13] suggested the concept of F-contraction and obtained a fixed point result which is a generalization of the Banach contraction principle. Afterward, Hunwisai and Kumam [4] introduced the concept of multivalued fuzzy F-contraction mappings in b-metic spaces and gave some fixed point results. Moreover, the notion of generalized F-Suzuki-contractions as a generalization of the concept of F-contractions was introduced by Piri and Kumam [9].

The notion of b-metric spaces as a generalization of metric spaces was introduced by Bakhtin [1]. In 1993, Czerwik [3] extended results related to the b-metric spaces. Since then, many authors have studied fixed point theorems for single-valued and multi-valued operators in b-metric spaces. Roshana et al. [10] suggested the concept of b-rectangular metric spaces as a generalization of b-metric spaces. In addition, Sookprasert et al. [12] extended results related to the b-rectangular metric spaces. On the other hand,

\footnotetext{
*Corresponding author

Email addresses: panisa.1@hotmail.com (Panisa Lohawech), anchaleeka@nu.ac.th (Anchalee Kaewcharoen)

doi: $10.22436 /$ jnsa.012.11.04
}

Received: 2017-04-07 Revised: 2019-03-01 Accepted: 2019-03-05 
the study of fixed points in partial metric spaces as a generalization of metric spaces was introduced by Matthews [7] in 1994.

After that, Shukla [11] presented the notion of partial b-metric spaces, which is a generalization of partial metric spaces and b-metric spaces as follows:

Definition 1.1 ([11]). Let $X$ be a nonempty set and $s \geqslant 1$ be a given real number. A function $p_{b}: X \times X \rightarrow$ $\mathbb{R}_{+}$is called a partial b-metric if for all $x, y, z \in X$ the following properties hold:

$\left(p_{b 1}\right) x=y$ if and only if $p_{b}(x, x)=p_{b}(x, y)=p_{b}(y, y)$;

$\left(\mathrm{p}_{\mathrm{b} 2}\right) \mathrm{p}_{\mathrm{b}}(x, x) \leqslant \mathrm{p}_{\mathrm{b}}(x, y)$;

$\left(\mathrm{p}_{\mathrm{b} 3}\right) \mathrm{p}_{\mathrm{b}}(\mathrm{x}, \mathrm{y})=\mathrm{p}_{\mathrm{b}}(\mathrm{y}, \mathrm{x})$;

$\left(p_{\mathrm{b} 4}\right) p_{\mathrm{b}}(x, y) \leqslant s\left[p_{\mathrm{b}}(x, z)+p_{\mathrm{b}}(y, z)\right]-p_{\mathrm{b}}(z, z)$.

The pair $\left(X, p_{b}\right)$ is called a partial b-metric space.

The class of partial b-metric spaces is larger than the class of partial metric spaces, since a partial metric space is a special case of a partial $b$-metric space with the coefficient $s=1$. Also, the class of partial $b$-metric spaces is larger than the class of $b$-metric spaces since a $b$-metric space is a special case of a partial b-metric space with the same coefficient and the self distance $p_{b}(x, x)=0$.

The following example shows that a partial $b$-metric space need not be a partial metric space nor a b-metric space.

Example 1.2 ([11]). Let $X=\mathbb{R}_{+}$and $q>1$ be a constant. Define a function $p_{b}: X \times X \rightarrow \mathbb{R}_{+}$by

$$
p_{b}(x, y)=[\max \{x, y\}]^{q}+|x-y|^{q} \quad \text { for all } x, y \in X .
$$

Then $\left(X, p_{b}\right)$ is a partial b-metric space with the coefficient $s=2^{q-1}>1$, but it is neither a partial metric space nor a $b$-metric space.

Proposition 1.3 ([11]). Let $\mathrm{X}$ be a nonempty set, $\mathrm{p}$ be a partial metric and $\mathrm{d}$ be a b-metric with the coefficient $\mathrm{s} \geqslant 1$ on $\mathrm{X}$. Then the function $\mathrm{p}_{\mathrm{b}}: \mathrm{X} \times \mathrm{X} \rightarrow \mathbb{R}_{+}$, defined by $\mathrm{p}_{\mathrm{b}}(\mathrm{x}, \mathrm{y})=\mathrm{p}(\mathrm{x}, \mathrm{y})+\mathrm{d}(\mathrm{x}, \mathrm{y})$ for all $\mathrm{x}, \mathrm{y} \in \mathrm{X}$, is a partial $\mathrm{b}$-metric with the coefficient $\mathrm{s}$.

Proposition $1.4([11])$. Let $(\mathrm{X}, \mathrm{p})$ be a partial metric space and $\mathrm{q} \geqslant 1$. Then $\left(\mathrm{X}, \mathrm{p}_{\mathrm{b}}\right)$ is a partial $\mathrm{b}$-metric space with the coefficient $s=2^{q-1}$, where $\mathrm{p}_{\mathrm{b}}: \mathrm{X} \times \mathrm{X} \rightarrow \mathbb{R}_{+}$is defined by $\mathrm{p}_{\mathrm{b}}(\mathrm{x}, \mathrm{y})=[\mathrm{p}(\mathrm{x}, \mathrm{y})]^{\mathrm{q}}$.

Mustafa et al. [8] introduced a modified version of Definition 1.1 in order to get that each partial b-metric $p_{b}$ generates a b-metric $d_{p_{b}}$.

Definition 1.5 ([8]). Let $X$ be a nonempty set and $s \geqslant 1$ be a given real number. A function $p_{b}: X \times X \rightarrow$ $\mathbb{R}_{+}$is called a partial b-metric if for all $x, y, z \in X$ the following properties hold:

$\left(p_{b 1}\right) x=y$ if and only if $p_{b}(x, x)=p_{b}(x, y)=p_{b}(y, y)$;

$\left(\mathrm{p}_{\mathrm{b} 2}\right) \mathrm{p}_{\mathrm{b}}(x, x) \leqslant \mathrm{p}_{\mathrm{b}}(x, y)$;

$\left(p_{\mathrm{b} 3}\right) p_{\mathrm{b}}(x, y)=p_{\mathrm{b}}(y, x)$;

$\left(p_{b 4^{\prime}}\right) p_{b}(x, y) \leqslant s\left(p_{b}(x, z)+p_{b}(y, z)-p_{b}(z, z)\right)+\left(\frac{1-s}{2}\right)\left(p_{b}(x, x)+p_{b}(y, y)\right)$.

The pair $\left(X, p_{b}\right)$ is called a partial $b$-metric space.

Since $s \geqslant 1$, by $\left(\mathrm{p}_{\mathrm{b} 4^{\prime}}\right)$, we obtain that

$$
p_{\mathrm{b}}(x, y) \leqslant s\left(p_{\mathrm{b}}(x, z)+p_{\mathrm{b}}(z, y)-p_{\mathrm{b}}(z, z)\right) \leqslant s\left(p_{\mathrm{b}}(x, z)+p_{\mathrm{b}}(z, y)\right)-p_{\mathrm{b}}(z, z) .
$$

Thus, a partial b-metric in the sense of Definition 1.5 is also a partial b-metric in Definition 1.1. 
In a partial b-metric space $\left(X, p_{b}\right)$, if $p_{b}(x, y)=0$ implies $p_{b}(x, x)=p_{b}(x, y)=p_{b}(y, y)=0$, then $x=y$, but if $x=y$, then $p_{b}(x, y)$ may not be 0 . It is clear that every partial metric space is a partial $b$-metric space with the coefficient $s=1$ and every $b$-metric space is a partial $b$-metric space with the same coefficient and the self distance $p_{b}(x, x)=0$, but the converse of these facts may not hold.

The following example shows that a partial b-metric space (Definition 1.5) need not to be a partial metric space nor a b-metric space.

Example 1.6 ([8]). Let $(X, d)$ be a metric space and $p_{b}: X \times X \rightarrow \mathbb{R}_{+}$defined by

$$
p_{b}(x, y)=d(x, y)^{q}+a \quad \text { for all } x, y \in X,
$$

where $q>1$ and $a \geqslant 0$. Then $p_{b}$ is a partial b-metric with $s=2^{q-1}$, but it is neither a partial metric nor b-metric.

Proposition 1.7 ([8]). Every partial b-metric $\mathrm{p}_{\mathrm{b}}$ defines a b-metric $\mathrm{d}_{\mathrm{p}_{\mathrm{b}}}$, where

$$
d_{p_{b}}(x, y)=2 p_{b}(x, y)-p_{b}(x, x)-p_{b}(y, y) \quad \text { for all } x, y \in X .
$$

Definition 1.8 ([8]). Let $\left\{x_{n}\right\}$ be a sequence in a partial b-metric space $\left(X, p_{b}\right)$.

(i) A sequence $\left\{x_{n}\right\}$ is $p_{b}$-convergent to a point $x \in X$ if $\lim _{n \rightarrow \infty} p_{b}\left(x, x_{n}\right)=p_{b}(x, x)$.

(ii) A sequence $\left\{x_{n}\right\}$ is a $p_{b}$-Cauchy sequence if $\lim _{n, m \rightarrow \infty} p_{b}\left(x_{n}, x_{m}\right)$ exists (and is finite).

(iii) A partial b-metric space $\left(X, p_{b}\right)$ is said to be $p_{b}$-complete if every $p_{b}$-Cauchy sequence $\left\{x_{n}\right\}$ in $X$ $p_{b}$-converges to a point $x \in X$ such that $\lim _{n, m \rightarrow \infty} p_{b}\left(x_{n}, x_{m}\right)=\lim _{n \rightarrow \infty} p_{b}\left(x_{n}, x\right)=p_{b}(x, x)$.

Lemma 1.9 ([8]).

(1) A sequence $\left\{x_{n}\right\}$ is a $p_{b}$-Cauchy sequence in a partial b-metric space $\left(X, p_{b}\right)$ if and only if it is a b-Cauchy sequence in the b-metric space $\left(X, \mathrm{~d}_{\mathfrak{p}_{\mathrm{b}}}\right)$.

(2) A partial b-metric space $\left(\mathrm{X}, \mathrm{p}_{\mathrm{b}}\right)$ is $\mathrm{p}_{\mathrm{b}}$-complete if and only if a $\mathrm{b}$-metric space $\left(\mathrm{X}, \mathrm{d}_{\mathrm{p}_{\mathrm{b}}}\right)$ is $\mathrm{b}$-complete. Moreover, $\lim _{n \rightarrow \infty} d_{p_{b}}\left(x, x_{n}\right)=0$ if and only if

$$
\lim _{n \rightarrow \infty} p_{b}\left(x, x_{n}\right)=\lim _{n, m \rightarrow \infty} p_{b}\left(x_{n}, x_{m}\right)=p_{b}(x, x) .
$$

Definition 1.10 ([8]). Let $\left(X, p_{b}\right)$ and $\left(X^{\prime}, p_{b}^{\prime}\right)$ be two partial b-metric spaces and let $f:\left(X, p_{b}\right) \rightarrow\left(X^{\prime}, p_{b}^{\prime}\right)$ be a mapping. Then $f$ is said to be $p_{b}$-continuous at a point $a \in X$ if for a given $\varepsilon>0$, there exists $\delta>0$ such that $x \in X$ and $p_{b}(a, x)<\delta+p_{b}(a, a)$ imply that $p_{b}^{\prime}(f(a), f(x))<\varepsilon+p_{b}^{\prime}(f(a), f(a))$. The mapping $f$ is $p_{b}$-continuous on $X$ if it is $p_{b}$-continuous at all $a \in X$.

Proposition $1.11([8])$. Let $\left(X, p_{b}\right)$ and $\left(X^{\prime}, p_{b}^{\prime}\right)$ be two partial b-metric spaces. Then a mapping $f: X \rightarrow X$ is $\mathrm{p}_{\mathrm{b}}$-continuous at a point $\mathrm{x} \in \mathrm{X}$ if and only if it is $\mathrm{p}_{\mathrm{b}}$-sequentially continuous at $\mathrm{x}$, that is, whenever $\left\{\mathrm{x}_{\mathrm{n}}\right\}$ is $\mathrm{p}_{\mathrm{b}}$-convergent to $\mathrm{x},\left\{\mathrm{f}\left(\mathrm{x}_{\mathrm{n}}\right)\right\}$ is $\mathrm{p}_{\mathrm{b}}^{\prime}$-convergent to $\mathrm{f}(\mathrm{x})$.

Recently, the notion of JS-quasi-contractions was introduced by Li and Jiang [6]. They proved some fixed point results for JS-quasi-contractions in complete metric spaces.

Following Hussain et al. [5], Li and Jiang [6] denoted $\Psi$ by the set of all nondecreasing functions $\psi:[0,+\infty) \rightarrow[1,+\infty)$ satisfying the following conditions:

( $\Psi 1) \psi(t)=1$ if and only if $t=0$;

$(\Psi 2)$ for each sequence $\left\{t_{n}\right\} \subset(0,+\infty), \lim _{n \rightarrow \infty} \psi\left(t_{n}\right)=1$ if and only if $\lim _{n \rightarrow \infty} t_{n}=0$; 


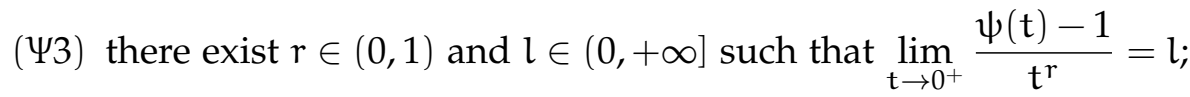

$(\Psi 4) \psi(t+s) \leqslant \psi(t) \psi(s)$ for all $t, s>0$.

Li and Jiang [6] set the following symbols:

$\Phi_{1}=\{\psi:(0,+\infty) \rightarrow(1,+\infty): \psi$ is a nondecreasing function satisfying ( $\Psi 2)$ and $\left.(\Psi 3)\right\} ;$

$\Phi_{2}=\{\psi:(0,+\infty) \rightarrow(1,+\infty): \psi$ is a nondecreasing continuous function $\} ;$

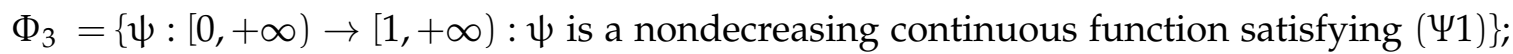

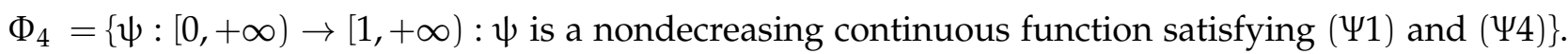

They [6] presented the following examples for illustrating the relationship among the above sets.

Example 1.12 ([6]). Let $f(t)=e^{t e^{t}}$ for $t \geqslant 0$. Then $f \in \Phi_{2} \cap \Phi_{3}$, but $f \notin \Psi \cup \Phi_{1} \cup \Phi_{4}$ since $\lim _{t \rightarrow 0^{+}} \frac{e^{t e^{t}}-1}{t^{r}}=0$ for each $r \in(0,1)$ and $e^{(t+s) e^{(t+s)}}>e^{s e^{s}} e^{t e^{t}}$ for all $s, t>0$.

Example $1.13([6])$. Let $g(t)=e^{t^{a}}$ for $t \geqslant 0$, where $a>0$. When $a \in(0,1), g \in \Psi \cap \Phi_{1} \cap \Phi_{2} \cap \Phi_{3} \cap \Phi_{4}$. When $a=1, g \in \Phi_{2} \cap \Phi_{3} \cap \Phi_{4}$, but $g \notin \Psi \cup \Phi_{1}$ since $\lim _{t \rightarrow 0^{+}} \frac{e^{t}-1}{t^{r}}=0$ for each $r \in(0,1)$. When $a>1, g \in \Phi_{2} \cap \Phi_{3}$, but $g \notin \Psi \cup \Phi_{1} \cup \Phi_{4}$ since $\lim _{t \rightarrow 0^{+}} \frac{e^{t^{a}}-1}{t^{r}}=0$ for each $r \in(0,1)$ and $e^{(t+s)^{a}}>e^{t^{a}} e^{s^{a}}$ for all $s, t>0$.

They [6] introduced the concept of JS-quasi-contractions and assure the existence of the fixed point theorems for such mappings in complete metric spaces.

Definition 1.14 ([6]). Let $(X, d)$ be a metric space. A mapping $T: X \rightarrow X$ is said to be a JS-quasi-contraction if there exist a function $\psi:(0,+\infty) \rightarrow(1,+\infty)$ and $\lambda \in(0,1)$ such that

$$
\psi(d(T x, T y)) \leqslant \psi\left(M_{d}(x, y)\right)^{\lambda} \quad \text { for all } x, y \in X \text { with } T x \neq T y
$$

where $M_{d}(x, y)=\max \left\{d(x, y), d(x, T x), d(y, T y), \frac{d(x, T y)+d(y, T x)}{2}\right\}$.

Remark $1.15([6])$. Let $\mathrm{T}: \mathrm{X} \rightarrow \mathrm{X}$ and $\psi:[0,+\infty) \rightarrow[1,+\infty)$ be such that

$$
\psi(d(T x, T y)) \leqslant \psi(d(x, y))^{k_{1}} \psi(d(x, T x))^{k_{2}} \psi(d(y, T y))^{k_{3}} \psi\left(\frac{d(x, T y)+d(y, T x)}{2}\right)^{2 k_{4}} \quad \text { for all } x, y \in X,
$$

where $k_{1}, k_{2}, k_{3}, k_{4}$ are nonnegative numbers with $k_{1}+k_{2}+k_{3}+2 k_{4}<1$. Then $T$ is a JS-quasi-contraction with $\lambda=k_{1}+k_{2}+k_{3}+2 k_{4}$, provided that ( $\left.\Psi 2\right)$ is satisfied.

Theorem 1.16 ([6]). Let $(X, \mathrm{~d})$ be a complete metric space and $\mathrm{T}: \mathrm{X} \rightarrow \mathrm{X}$ be a JS-quasi-contraction with $\psi \in \Phi_{2}$. Then $\mathrm{T}$ has a unique fixed point in $\mathrm{X}$.

Theorem $1.17([6])$. Let $(\mathrm{X}, \mathrm{d})$ be a complete metric space and $\mathrm{T}: \mathrm{X} \rightarrow \mathrm{X}$. Assume that there exist $\psi \in \Phi_{3}$ and nonnegative numbers $\mathrm{k}_{1}, \mathrm{k}_{2}, \mathrm{k}_{3}, \mathrm{k}_{4}$ with $\mathrm{k}_{1}+\mathrm{k}_{2}+\mathrm{k}_{3}+2 \mathrm{k}_{4}<1$ such that (1.1) is satisfied. Then $\mathrm{T}$ has a unique fixed point in $\mathrm{X}$.

In this paper, we introduce a concept of generalized JS-quasi-contractions and obtain sufficient conditions for the existence of fixed points of such mappings on $p_{b}$-complete partial b-metric spaces. Our results extend the results in the literature. In addition, an example is given to illustrate and support our main result. 


\section{Main result}

We now introduce the concept of generalized JS-quasi-contractions on partial b-metric spaces.

Definition 2.1. Let $\left(X, p_{b}\right)$ be a partial $b$-metric space with the coefficient $s \geqslant 1$. We say that a mapping $\mathrm{T}: \mathrm{X} \rightarrow \mathrm{X}$ is a generalized JS-quasi-contraction if there exist a function $\psi:(0,+\infty) \rightarrow(1,+\infty)$ and $\lambda \in(0,1)$ such that

$$
\psi\left(\operatorname{sp}_{\mathrm{b}}(T x, T y)\right) \leqslant \psi\left(M_{s}(x, y)\right)^{\lambda} \text { for all } x, y \in X \text { with } T x \neq T y
$$

where $M_{s}(x, y)=\max \left\{p_{b}(x, y), p_{b}(x, T x), p_{b}(y, T y), \frac{p_{b}(x, T y)+p_{b}(y, T x)}{2 s}\right\}$.

The following example shows that a generalized JS-quasi-contraction need not to be $p_{\mathrm{b}}$-continuous.

Example 2.2. Let $X=[0,+\infty)$ with the partial b-metric $p_{\mathrm{b}}: X \times X \rightarrow \mathbb{R}_{+}$defined by

$$
p_{b}(x, y)=[\max \{x, y\}]^{2}
$$

for all $x, y \in X$. Obviously, $\left(X, p_{b}\right)$ is a $p_{b}$-complete partial $b$-metric space with $s=2$. Define the mapping $\mathrm{T}: \mathrm{X} \rightarrow \mathrm{X}$ by

$$
T x= \begin{cases}\frac{2}{3}, & x \in[0,1) \\ \frac{x-1}{2 x}, & \text { otherwise. }\end{cases}
$$

We will show that $T$ is a generalized JS-quasi-contraction with $\psi(t)=e^{t} \in \Phi_{2}$. In fact, it suffices to show that there exists $\lambda \in(0,1)$ such that, for all $x, y \in X$ with $T x \neq T y$,

$$
\frac{2 p_{b}(T x, T y)}{M_{s}(x, y)} \leqslant \lambda
$$

Let $x, y \in X$ with $T x \neq T y$. Without loss of generality, we may assume that $x<y$. It follows that $1 \leqslant x<y$. Therefore,

and

$$
p_{b}(T x, T y)=\left[\max \left\{\frac{x-1}{2 x}, \frac{y-1}{2 y}\right\}\right]^{2}=\frac{y^{2}-2 y+1}{4 y^{2}}
$$

$$
M_{s}(x, y)=\max \left\{y^{2}, x^{2}, y^{2}, \frac{\left[\max \left\{x, \frac{y-1}{2 y}\right\}\right]^{2}+y^{2}}{2 s}\right\}=y^{2}
$$

This implies that

$$
\frac{2 p_{b}(T x, T y)}{M_{s}(x, y)}=\frac{y^{2}-2 y+1}{2 y^{4}} \leqslant \frac{1}{32}
$$

This shows that $T$ is a generalized JS-quasi-contraction with $\psi(t)=e^{t} \in \Phi_{2}$ and $\lambda \in\left[\frac{1}{32}, 1\right)$.

On the other hand, $T$ is not $p_{b}$-continuous because there exists a sequence $\left\{\frac{1}{n+1}\right\}$ such that

$$
\lim _{n \rightarrow \infty} p_{b}\left(1, x_{n}\right)=\lim _{n \rightarrow \infty}\left[\max \left\{1, x_{n}\right\}\right]^{2}=1=p_{b}(1,1),
$$

but

$$
\lim _{n \rightarrow \infty} p_{b}\left(T 1, T x_{n}\right)=\left[\max \left\{0, \frac{2}{3}\right\}\right]^{2}=\frac{4}{9} \neq 0=p_{b}(T 1, T 1) .
$$

The following example shows that a $\mathrm{p}_{\mathrm{b}}$-continuous mapping need not to be a generalized JS-quasicontraction. 
Example 2.3. Let $X=\{0,1,2\}$ with the partial b-metric $p_{b}: X \times X \rightarrow \mathbb{R}_{+}$defined by

$$
p_{b}(x, y)=|x-y|^{2}
$$

for all $x, y \in X$. Obviously, $\left(X, p_{b}\right)$ is a $p_{b}$-complete partial $b$-metric space with $s=2$. Define the mapping $\mathrm{T}: \mathrm{X} \rightarrow \mathrm{X}$ by $\mathrm{T} 0=\mathrm{T} 1=0$ and $\mathrm{T} 2=1$. Then $\mathrm{T}$ is $\mathrm{p}_{\mathrm{b}}$-continuous.

We will show that $T$ is not a generalized JS-quasi-contraction with $\psi(t)=e^{t e^{t}} \in \Phi_{2}$. In fact, it suffices to show that for all $\lambda \in(0,1)$, there exist $x, y \in X$ with $T x \neq T y$ such that

$$
\frac{2 p_{b}(T x, T y) e^{2 p_{b}(T x, T y)-M_{s}(x, y)}}{M_{s}(x, y)}>\lambda
$$

Let $\lambda \in(0,1)$, for $x=1$ and $y=2$, we have $p_{b}(T 1, T 2)=1$ and $M_{s}(1,2)=1$. Therefore,

$$
\frac{2 p_{\mathrm{b}}(\mathrm{T} 1, \mathrm{~T} 2) e^{2 \mathrm{p}_{\mathrm{b}}(\mathrm{T} 1, \mathrm{~T} 2)-M_{\mathrm{s}}(1,2)}}{M_{\mathrm{s}}(1,2)}=2(1) e^{2-1}=2 e>\lambda,
$$

which implies that $\mathrm{T}$ is not a generalized JS-quasi-contraction.

Remark 2.4. As in [6], we obtain the following statements in a partial b-metric space $\left(X, p_{b}\right)$ :

(i) Let $\mathrm{T}: \mathrm{X} \rightarrow \mathrm{X}$ and $\lambda \in(0,1)$ such that

$$
\operatorname{sp}_{\mathrm{b}}(T x, T y) \leqslant \lambda M_{s}(x, y) \text { for all } x, y \in X .
$$

Then $T$ is a generalized JS-quasi-contraction with $\psi(t)=e^{t}$.

(ii) Let $\mathrm{T}: \mathrm{X} \rightarrow \mathrm{X}$ and $\psi:(0,+\infty) \rightarrow(1,+\infty)$ be such that

$$
\psi\left(\operatorname{sp}_{\mathrm{b}}(T x, T y)\right) \leqslant \psi\left(p_{b}(x, y)\right)^{\lambda} \quad \text { for all } x, y \in X \text { with } T x \neq T y,
$$

where $\lambda \in(0,1)$. Then $T$ is a generalized JS-quasi-contraction.

(iii) Let $T: X \rightarrow X$ and $\psi:[0,+\infty) \rightarrow[1,+\infty)$ be such that

$$
\psi\left(\operatorname{sp}_{\mathfrak{b}}(T x, T y)\right) \leqslant \psi\left(p_{b}(x, y)\right)^{k_{1}} \psi\left(p_{b}(x, T x)\right)^{k_{2}} \psi\left(p_{b}(y, T y)\right)^{k_{3}} \psi\left(\frac{p_{b}(x, T y)+p_{b}(y, T x)}{2 s}\right)^{2 k_{4}}
$$

for all $x, y \in X$, where $k_{1}, k_{2}, k_{3}, k_{4}$ are nonnegative numbers with $k_{1}+k_{2}+k_{3}+2 k_{4}<1$. Then $T$ is a generalized JS-quasi-contraction with $\lambda=k_{1}+k_{2}+k_{3}+2 k_{4}$, provided that ( $\left.\Psi 1\right)$ is satisfied.

(iv) Let $T: X \rightarrow X$ and $\psi:[0,+\infty) \rightarrow[1,+\infty)$ be such that

$$
\psi\left(\operatorname{sp}_{\mathfrak{b}}(T x, T y)\right) \leqslant \psi\left(p_{b}(x, y)\right)^{k_{1}} \psi\left(p_{b}(x, T x)\right)^{k_{2}} \psi\left(p_{b}(y, T y)\right)^{k_{3}} \psi\left(\frac{p_{b}(x, T y)+p_{b}(y, T x)}{s}\right)^{k_{4}}
$$

for all $x, y \in X$. Suppose that $\psi$ is a nondecreasing function such that ( $\Psi 4)$ is satisfied. It follows that

$$
\psi\left(\frac{p_{b}(x, T y)+p_{b}(y, T x)}{s}\right)^{k_{4}} \leqslant \psi\left(\frac{p_{b}(x, T y)+p_{b}(y, T x)}{2 s}\right)^{2 k_{4}} \quad \text { for all } x, y \in X,
$$

and so (2.3) holds. Moreover, if ( $\Psi 1)$ is satisfied, then it follows from (iii) that $T$ is a generalized JS-quasi-contraction with $\lambda=k_{1}+k_{2}+k_{3}+2 k_{4}$. Therefore, $T$ is a generalized JS-quasi-contraction with $\psi \in \Phi_{4}$ or $\psi \in \Psi$.

We now prove the existence of a unique fixed point for a generalized JS-quasi-contraction. 
Theorem 2.5. Let $\left(\mathrm{X}, \mathrm{p}_{\mathrm{b}}\right)$ be a $\mathrm{p}_{\mathrm{b}}$-complete partial b-metric space with the coefficient $\mathrm{s} \geqslant 1$. Let $\mathrm{T}: \mathrm{X} \rightarrow \mathrm{X}$ be a generalized JS-quasi-contraction with $\psi \in \Phi_{2}$ and be $\mathrm{p}_{\mathrm{b}}$-continuous. Then $\mathrm{T}$ has a unique fixed point in $\mathrm{X}$.

Proof. Let $x_{0} \in X$. Define a sequence $\left\{x_{n}\right\}$ in $X$ by $x_{n}=T^{n} x_{0}$ for all $n \in \mathbb{N}$. If there exists $n \in \mathbb{N}$ such that $x_{n}=x_{n+1}$ then $x_{n}$ is a fixed point of $T$ and the proof is finished. So we may assume that for every $n \in \mathbb{N}$,

$$
x_{n} \neq x_{n+1} .
$$

From (2.1), (2.5), and $\psi$ is nondecreasing, we have

$$
\psi\left(p_{b}\left(x_{n}, x_{n+1}\right)\right) \leqslant \psi\left(s p_{b}\left(x_{n}, x_{n+1}\right)\right) \leqslant \psi\left(M_{s}\left(x_{n-1}, x_{n}\right)\right)^{\lambda}
$$

for all $n \in \mathbb{N}$, where

$$
\begin{aligned}
M_{s}\left(x_{n-1}, x_{n}\right)= & \max \left\{p_{b}\left(x_{n-1}, x_{n}\right), p_{b}\left(x_{n-1}, T x_{n-1}\right), p_{b}\left(x_{n}, T x_{n}\right), \frac{p_{b}\left(x_{n-1}, T x_{n}\right)+p_{b}\left(x_{n}, T x_{n-1}\right)}{2 s}\right\} \\
= & \max \left\{p_{b}\left(x_{n-1}, x_{n}\right), p_{b}\left(x_{n-1}, x_{n}\right), p_{b}\left(x_{n}, x_{n+1}\right), \frac{p_{b}\left(x_{n-1}, x_{n+1}\right)+p_{b}\left(x_{n}, x_{n}\right)}{2 s}\right\} \\
\leqslant & \max \left\{p_{b}\left(x_{n-1}, x_{n}\right), p_{b}\left(x_{n}, x_{n+1}\right)\right. \\
& \left., \frac{s\left(p_{b}\left(x_{n-1}, x_{n}\right)+p_{b}\left(x_{n}, x_{n+1}\right)\right)-p_{b}\left(x_{n}, x_{n}\right)+p_{b}\left(x_{n}, x_{n}\right)}{2 s}\right\} \\
= & \max \left\{p_{b}\left(x_{n-1}, x_{n}\right), p_{b}\left(x_{n}, x_{n+1}\right), \frac{p_{b}\left(x_{n-1}, x_{n}\right)+p_{b}\left(x_{n}, x_{n+1}\right)}{2}\right\} \\
= & \max \left\{p_{b}\left(x_{n-1}, x_{n}\right), p_{b}\left(x_{n}, x_{n+1}\right)\right\} .
\end{aligned}
$$

This implies that

$$
\psi\left(p_{b}\left(x_{n}, x_{n+1}\right)\right) \leqslant \psi\left(s p_{b}\left(x_{n}, x_{n+1}\right)\right) \leqslant \psi\left(\max \left\{p_{b}\left(x_{n-1}, x_{n}\right), p_{b}\left(x_{n}, x_{n+1}\right)\right\}\right)^{\lambda}
$$

for all $n \in \mathbb{N}$. If there exists some $n \in \mathbb{N}$ such that $p_{b}\left(x_{n}, x_{n+1}\right)>p_{b}\left(x_{n-1}, x_{n}\right)$, then

$$
\psi\left(p_{b}\left(x_{n}, x_{n+1}\right)\right) \leqslant \psi\left(p_{b}\left(x_{n}, x_{n+1}\right)\right)^{\lambda}<\psi\left(p_{b}\left(x_{n}, x_{n+1}\right)\right),
$$

which is a contradiction. It follows that

$$
p_{b}\left(x_{n}, x_{n+1}\right) \leqslant p_{b}\left(x_{n-1}, x_{n}\right)
$$

for all $n \in \mathbb{N}$. So the sequence $\left\{p_{b}\left(x_{n}, x_{n+1}\right)\right\}$ is a nonincreasing sequence of real numbers which is bounded from below and thus there exists $\alpha \geqslant 0$ such that

$$
\lim _{n \rightarrow \infty} p_{b}\left(x_{n}, x_{n+1}\right)=\alpha \text { and } p_{b}\left(x_{n}, x_{n+1}\right) \geqslant \alpha .
$$

Suppose that $\alpha>0$. From (2.6), (2.7), and $\psi$ being nondecreasing, we obtain that

$$
1<\psi(\alpha) \leqslant \psi\left(p_{b}\left(x_{n}, x_{n+1}\right)\right) \leqslant \psi\left(p_{b}\left(x_{n-1}, x_{n}\right)\right)^{\lambda} \leqslant \cdots \leqslant \psi\left(p_{b}\left(x_{0}, x_{1}\right)\right)^{\lambda^{n}}
$$

for all $n \in \mathbb{N}$. Letting $n \rightarrow \infty$ in (2.8), we have $1<\psi(\alpha) \leqslant 1$, which is a contradiction. Thus $\alpha=0$ and this yields

$$
\lim _{n \rightarrow \infty} p_{b}\left(x_{n}, x_{n+1}\right)=0 .
$$

Now, we show that $\left\{x_{n}\right\}$ is a $p_{b}$-Cauchy sequence in $\left(X, p_{b}\right)$ which is equivalent to show that $\left\{x_{n}\right\}$ is a $b$-Cauchy sequence in $\left(X, d_{p_{b}}\right)$. Suppose not, that is, there exist $\varepsilon>0$ and two subsequences $\left\{x_{m_{k}}\right\}$ and $\left\{x_{n_{k}}\right\}$ of $\left\{x_{n}\right\}$ such that $n_{k}$ is the smallest index with $n_{k}>m_{k}>k$ for which

$$
d_{p_{b}}\left(x_{m_{k}}, x_{n_{k}}\right) \geqslant \varepsilon
$$


and

$$
d_{p_{b}}\left(x_{m_{k}}, x_{n_{k}-1}\right)<\varepsilon
$$

This implies that

$$
\varepsilon \leqslant d_{p_{b}}\left(x_{m_{k}}, x_{n_{k}}\right) \leqslant s d_{p_{b}}\left(x_{m_{k}}, x_{n_{k}-1}\right)+s d_{p_{b}}\left(x_{n_{k}-1}, x_{n_{k}}\right)<s \varepsilon+s d_{p_{b}}\left(x_{n_{k}-1}, x_{n_{k}}\right) .
$$

Taking the upper limit as $k \rightarrow \infty$ in (2.11), we get that

$$
\frac{\varepsilon}{s} \leqslant \liminf _{k \rightarrow \infty} d_{\mathfrak{p}_{\mathfrak{b}}}\left(x_{\mathfrak{m}_{k}}, x_{n_{k}-1}\right) \leqslant \limsup _{k \rightarrow \infty} d_{\mathfrak{p}_{\mathfrak{b}}}\left(x_{\mathfrak{m}_{k}}, x_{\mathfrak{n}_{k}-1}\right) \leqslant \varepsilon .
$$

It follows from (2.12) that,

$$
\varepsilon \leqslant \limsup _{k \rightarrow \infty} d_{\mathfrak{p}_{\mathfrak{b}}}\left(x_{m_{k}}, x_{n_{k}}\right) \leqslant s \varepsilon .
$$

By using the triangular inequality, we have

$$
\begin{aligned}
d_{\mathfrak{p}_{\mathfrak{b}}}\left(x_{m_{k}+1}, x_{n_{k}}\right) & \leqslant s d_{p_{\mathfrak{b}}}\left(x_{m_{k}+1}, x_{m_{k}}\right)+s d_{p_{\mathfrak{b}}}\left(x_{m_{k}}, x_{n_{k}}\right) \\
& \leqslant s d_{p_{\mathfrak{b}}}\left(x_{m_{k}+1}, x_{m_{k}}\right)+s^{2} d_{p_{\mathfrak{b}}}\left(x_{m_{k}}, x_{n_{k}-1}\right)+s^{2} d_{p_{\mathfrak{b}}}\left(x_{n_{k}-1}, x_{n_{k}}\right) \\
& \leqslant s d_{\mathfrak{p}_{\mathfrak{b}}}\left(x_{m_{k}+1}, x_{m_{k}}\right)+s^{2} \varepsilon+s^{2} d_{\mathfrak{p}_{\mathfrak{b}}}\left(x_{n_{k}-1}, x_{n_{k}}\right) .
\end{aligned}
$$

Taking the upper limit as $k \rightarrow \infty$ in above inequality, we obtain that

$$
\limsup _{k \rightarrow \infty} d_{p_{b}}\left(x_{m_{k}+1}, x_{n_{k}}\right) \leqslant s^{2} \varepsilon
$$

Further,

$$
d_{p_{\mathfrak{b}}}\left(x_{m_{k}+1}, x_{n_{k}-1}\right) \leqslant s d_{p_{b}}\left(x_{m_{k}+1}, x_{m_{k}}\right)+s d_{p_{b}}\left(x_{m_{k}}, x_{n_{k}-1}\right) \leqslant s d_{p_{b}}\left(x_{m_{k}+1}, x_{m_{k}}\right)+s \varepsilon,
$$

and hence

$$
\limsup _{k \rightarrow \infty} d_{p_{b}}\left(x_{m_{k}+1}, x_{n_{k}-1}\right) \leqslant s \varepsilon .
$$

By Proposition 1.7 and (2.9), we deduce that

$$
\begin{aligned}
& \limsup _{k \rightarrow \infty} d_{p_{b}}\left(x_{m_{k}}, x_{n_{k}-1}\right)=\limsup _{k \rightarrow \infty}\left(2 p_{b}\left(x_{m_{k}}, x_{n_{k}-1}\right)-p_{b}\left(x_{m_{k}}, x_{m_{k}}\right)-p_{b}\left(x_{n_{k}-1}, x_{n_{k}-1}\right)\right) \\
& =2 \limsup _{k \rightarrow \infty} p_{b}\left(x_{m_{k}}, x_{n_{k}-1}\right) .
\end{aligned}
$$

Also, by (2.13) and (2.16), we get that

$$
\frac{\varepsilon}{2 s} \leqslant \liminf _{k \rightarrow \infty} p_{b}\left(x_{m_{k}}, x_{n_{k}-1}\right) \leqslant \limsup _{k \rightarrow \infty} p_{b}\left(x_{m_{k}}, x_{n_{k}-1}\right) \leqslant \frac{\varepsilon}{2} .
$$

In analogy to (2.16), by (2.12), (2.14), and (2.15), we can prove that

$$
\begin{aligned}
\limsup _{k \rightarrow \infty} p_{b}\left(x_{m_{k}}, x_{n_{k}}\right) & \leqslant \frac{s \varepsilon}{2}, \\
\frac{\varepsilon}{2 s} & \leqslant \limsup _{k \rightarrow \infty} p_{b}\left(x_{m_{k}+1}, x_{n_{k}}\right), \\
\limsup _{k \rightarrow \infty} p_{b}\left(x_{m_{k}+1}, x_{n_{k}-1}\right) & \leqslant \frac{s \varepsilon}{2} .
\end{aligned}
$$

By (2.17), (2.18), and (2.19), we obtain that

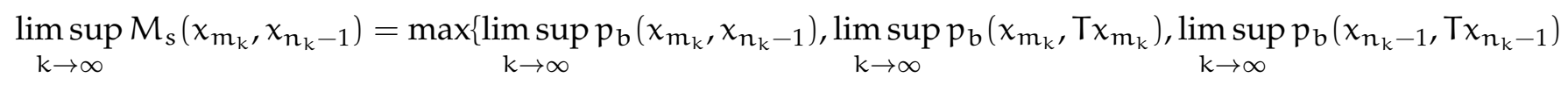




$$
\begin{aligned}
& \left.\quad \limsup _{k \rightarrow \infty} \frac{p_{b}\left(x_{m_{k}}, T x_{n_{k}-1}\right)+p_{b}\left(x_{n_{k}-1}, T x_{m_{k}}\right)}{2 s}\right\} \\
& \leqslant \max \left\{\limsup _{k \rightarrow \infty} p_{b}\left(x_{m_{k}}, x_{n_{k}-1}\right), 0,0, \limsup _{k \rightarrow \infty} \frac{p_{b}\left(x_{m_{k}}, x_{n_{k}}\right)+p_{b}\left(x_{n_{k}-1}, x_{m_{k}+1}\right)}{2 s}\right\} \\
& =\max \left\{\frac{\varepsilon}{2}, \frac{\varepsilon}{2}\right\}=\frac{\varepsilon}{2} .
\end{aligned}
$$

We claim that $x_{m_{k}+1} \neq x_{n_{k}}$. If $x_{m_{k}+1}=x_{n_{k}}$, then $d_{p_{b}}\left(x_{m_{k}+1}, x_{n_{k}}\right)=0$. From (2.10) and Proposition 1.7, we have

$$
\begin{aligned}
\varepsilon \leqslant d_{p_{b}}\left(x_{m_{k}}, x_{n_{k}}\right) & \leqslant \operatorname{sd}_{p_{b}}\left(x_{m_{k}}, x_{m_{k}+1}\right)+s d_{p_{b}}\left(x_{m_{k}+1}, x_{n_{k}}\right) \\
& =\operatorname{sd}_{p_{b}}\left(x_{m_{k}}, x_{m_{k}+1}\right) \\
& =s\left(2 p_{b}\left(x_{m_{k}}, x_{m_{k}+1}\right)-p_{b}\left(x_{m_{k}}, x_{m_{k}}\right)-p_{b}\left(x_{m_{k}+1}, x_{m_{k}+1}\right)\right) \\
& \leqslant 2 \operatorname{sp}_{b}\left(x_{m_{k}}, x_{m_{k}+1}\right) .
\end{aligned}
$$

Letting $k \rightarrow \infty$ and using (2.9), we deduce that

$$
\frac{\varepsilon}{2 s} \leqslant \lim _{k \rightarrow \infty} p_{b}\left(x_{m_{k}}, x_{m_{k}+1}\right)=0,
$$

which is a contradiction. It follows from (2.1) that

$$
\begin{aligned}
\psi\left(\frac{\varepsilon}{2}\right) \leqslant \psi\left(\operatorname{simsup} p_{b}\left(x_{m_{k}+1}, x_{n_{k}}\right)\right) & =\limsup _{k \rightarrow \infty} \psi\left(\operatorname{sp}_{b}\left(x_{m_{k}+1}, x_{n_{k}}\right)\right) \\
& \leqslant \limsup _{k \rightarrow \infty} \psi\left(M_{s}\left(x_{m_{k}}, x_{n_{k}-1}\right)\right)^{\lambda} \leqslant \psi\left(\frac{\varepsilon}{2}\right)^{\lambda}<\psi\left(\frac{\varepsilon}{2}\right),
\end{aligned}
$$

which is a contradiction. Thus $\left\{x_{n}\right\}$ is a b-Cauchy in b-metric space $\left(X, d_{p_{b}}\right)$. Since $\left(X, p_{b}\right)$ is $p_{b}$-complete, then $\left(X, d_{p_{b}}\right)$ is a $b$-complete $b$-metric space. So, there exists $z \in X$ such that $\lim _{n \rightarrow \infty} d_{p_{b}}\left(x_{n}, z\right)=0$. By Lemma 1.9 , we get that

$$
\lim _{n \rightarrow \infty} p_{b}\left(z, x_{n}\right)=p_{b}(z, z)
$$

By Proposition 1.7, (2.9), (2.20), and condition $\left(\mathrm{p}_{\mathrm{b} 2}\right)$, we have

$$
\lim _{n \rightarrow \infty} p_{b}\left(z, x_{n}\right)=\lim _{n \rightarrow \infty} p_{b}\left(x_{n}, x_{n}\right)=0 .
$$

Suppose that $z \neq T z$ implies that $p_{\mathrm{b}}(z, T z)>0$ and $d_{p_{b}}(z, T z)>0$. It follows from (2.9) and (2.21) that there exists a positive integer $n_{0}$ such that

$$
p_{b}\left(x_{n}, z\right) \leqslant \frac{p_{b}(z, T z)}{2} \quad \text { and } \quad p_{b}\left(x_{n}, x_{n+1}\right) \leqslant \frac{p_{b}(z, T z)}{2}
$$

for all $n \geqslant n_{0}$. This implies that

$$
\begin{aligned}
M_{s}\left(x_{n}, z\right) & =\max \left\{p_{b}\left(x_{n}, z\right), p_{b}\left(x_{n}, x_{n+1}\right), p_{b}(z, T z), \frac{p_{b}\left(x_{n}, T z\right)+p_{b}\left(z, x_{n+1}\right)}{2 s}\right\} \\
& \leqslant \max \left\{\frac{p_{b}(z, T z)}{2}, \frac{p_{b}(z, T z)}{2}, p_{b}(z, T z), p_{b}(z, T z)\right\}=p_{b}(z, T z)
\end{aligned}
$$

for all $n \geqslant n_{0}$. Since $T$ is $p_{b}$-continuous and (2.20), we obtain that

$$
\lim _{n \rightarrow \infty} p_{b}\left(x_{n+1}, T z\right)=p_{b}(T z, T z) .
$$

By the triangle inequality, we deduce that

$$
p_{b}(z, T z) \leqslant s p_{b}\left(z, x_{n+1}\right)+s p_{b}\left(x_{n+1}, T z\right)
$$


for all $n \in \mathbb{N}$. So by taking limit as $n \rightarrow \infty$ and using (2.23), we have

$$
p_{\mathrm{b}}(z, T z) \leqslant s \lim _{n \rightarrow \infty} p_{\mathrm{b}}\left(z, x_{n+1}\right)+s \lim _{n \rightarrow \infty} p_{\mathrm{b}}\left(x_{n+1}, T z\right)=\operatorname{sp}_{\mathrm{b}}(\mathrm{T} z, \mathrm{~T} z)
$$

If there are infinitely many $n \in \mathbb{N}$ such that $x_{n+1}=T z$, then $d_{p_{b}}\left(x_{n+1}, T z\right)=0$. This implies that

$$
d_{\mathfrak{p}_{\mathrm{b}}}(z, T z) \leqslant s d_{\mathfrak{p}_{\mathrm{b}}}\left(z, x_{n+1}\right)+s d_{\mathfrak{p}_{\mathrm{b}}}\left(x_{n+1}, T z\right)=s d_{\mathfrak{p}_{\mathrm{b}}}\left(z, x_{n+1}\right) .
$$

Letting $n \rightarrow \infty$, we get that $d_{p_{b}}(z, T z) \leqslant s \lim _{n \rightarrow \infty} d_{\mathfrak{p}_{b}}\left(z, x_{n+1}\right)=0$, which is a contradiction. This implies that there exists $n_{1} \in \mathbb{N}$ such that $x_{n+1} \neq T z$ for all $n \geqslant n_{1}$. Choose $N=\max \left\{n_{0}, n_{1}\right\}$. Thus, by (2.1) and (2.22), for each $n \geqslant N$, we get that

$$
\psi\left(\operatorname{sp}_{\mathrm{b}}\left(x_{n+1}, T z\right)\right) \leqslant \psi\left(M_{s}\left(x_{n}, z\right)\right)^{\lambda} \leqslant \psi\left(p_{b}(z, T z)\right)^{\lambda} .
$$

Letting $n \rightarrow \infty$ in this inequality, using the continuity of $\psi,(2.23)$, and (2.24), we obtain that

$$
\psi\left(p_{\mathrm{b}}(z, T z)\right) \leqslant \psi\left(\operatorname{sp}_{\mathrm{b}}(\mathrm{T} z, \mathrm{~T} z)\right)=\lim _{\mathrm{n} \rightarrow \infty} \psi\left(\operatorname{sp}_{\mathrm{b}}\left(x_{\mathrm{n}+1}, \mathrm{~T} z\right)\right) \leqslant \psi\left(\mathrm{p}_{\mathrm{b}}(z, \mathrm{~T} z)\right)^{\lambda}<\psi\left(\mathrm{p}_{\mathrm{b}}(z, \mathrm{~T} z)\right)
$$

which is a contradiction. Hence $T z=z$. Thus $z$ is a fixed point of $T$. Let $x$ be another fixed point of $T$ with $x \neq z$. It follows from (2.1) that

$$
\begin{aligned}
\psi\left(p_{\mathrm{b}}(x, z)\right) & \leqslant \psi\left(\operatorname{sp}_{\mathrm{b}}(T x, T z)\right) \\
& \leqslant p_{\mathrm{b}}\left(M_{\mathrm{s}}(x, z)\right)^{\lambda} \\
& =\psi\left(\max \left\{p_{\mathrm{b}}(x, z), p_{\mathrm{b}}(x, T x), p_{\mathrm{b}}(z, T z), \frac{p_{\mathrm{b}}(x, T z)+p_{\mathrm{b}}(z, T x)}{2 s}\right\}\right)^{\lambda} \\
& =\psi\left(\max \left\{p_{\mathrm{b}}(x, z), p_{\mathrm{b}}(x, x), p_{\mathrm{b}}(z, z), \frac{p_{\mathrm{b}}(x, z)+p_{\mathrm{b}}(z, x)}{2 s}\right\}\right)^{\lambda} \\
& =\psi\left(\max \left\{p_{\mathrm{b}}(x, z), p_{\mathrm{b}}(x, x), p_{\mathrm{b}}(z, z), \frac{p_{\mathrm{b}}(x, z)}{s}\right\}\right)^{\lambda} \\
& \leqslant \psi\left(\max \left\{p_{\mathrm{b}}(x, z), p_{\mathrm{b}}(x, z), p_{\mathrm{b}}(x, z), \frac{p_{\mathrm{b}}(x, z)}{s}\right\}\right)^{\lambda} \\
& =\psi\left(p_{\mathrm{b}}(x, z)\right)^{\lambda} \\
& <\psi\left(p_{\mathrm{b}}(x, z)\right)
\end{aligned}
$$

which is a contradiction. So $x=z$. Hence $T$ has a unique fixed point.

We illustrate the following example for supporting our result.

Example 2.6. Let $X=\{0,1,2\}$ with the partial b-metric $p_{b}: X \times X \rightarrow \mathbb{R}_{+}$defined by

$$
p_{b}(x, y)=[\max \{x, y\}]^{2}
$$

for all $x, y \in X$. Obviously, $\left(X, p_{b}\right)$ is a $p_{b}$-complete partial $b$-metric space with $s=2$, but it is not a metric on $X$. To see this, let $x=y=2$ then $p_{b}(2,2)=[\max \{2,2\}]^{2}=4 \neq 0$. Define the mapping $T: X \rightarrow X$ by $\mathrm{T} 0=\mathrm{T} 1=0$ and $\mathrm{T} 2=1$.

We will show that $T$ is a generalized JS-quasi-contraction with $\psi(t)=e^{t e^{t}}$. In fact, it suffices to prove that there exists $\lambda \in(0,1)$ such that, for all $x, y \in X$ with $T x \neq T y$,

$$
\frac{2 p_{b}(T x, T y) e^{2 p_{b}(T x, T y)-M_{s}(x, y)}}{M_{s}(x, y)} \leqslant \lambda .
$$

Let $x, y \in X$ with $T x \neq T y$. Therefore, $x=0, y=2$ or $x=1, y=2$. For both cases, we get $p_{b}(T 0, T 2)=$ $p_{b}(T 1, T 2)=1$ and $M_{s}(0,2)=M_{s}(1,2)=4$. This implies that

$$
\frac{2 p_{\mathrm{b}}(\mathrm{T} 0, \mathrm{~T} 2) e^{2 p_{\mathrm{b}}(\mathrm{T} 0, \mathrm{~T} 2)-M_{s}(0,2)}}{M_{s}(0,2)}=\frac{2 p_{\mathrm{b}}(\mathrm{T} 1, \mathrm{~T} 2) e^{2 p_{\mathrm{b}}(\mathrm{T} 1, \mathrm{~T} 2)-\mathrm{M}_{\mathrm{s}}(1,2)}}{M_{s}(1,2)}=\frac{e^{-2}}{2}
$$


This shows that $T$ is a generalized JS-quasi-contraction with $\psi(t)=e^{t e^{t}}$ and $\lambda \in\left[\frac{e^{-2}}{2}, 1\right)$. By Example 1.12, we know that $e^{t e^{t}} \in \Phi_{2}$. Therefore, the conclusion immediately follows from Theorem 2.5 to obtain that $\mathrm{T}$ has a unique fixed point which is $x=0$.

Theorem 2.7. Let $\left(\mathrm{X}, \mathrm{p}_{\mathrm{b}}\right)$ be a $\mathrm{p}_{\mathrm{b}}$-complete partial b-metric space with the coefficient $\mathrm{s} \geqslant 1$. Let $\mathrm{T}: \mathrm{X} \rightarrow \mathrm{X}$ be a $\mathrm{p}_{\mathrm{b}}$-continuous mapping. Assume that there exist a function $\psi \in \Phi_{3}$ and nonnegative numbers $\mathrm{k}_{1}, \mathrm{k}_{2}, \mathrm{k}_{3}, \mathrm{k}_{4}$ with $\mathrm{k}_{1}+\mathrm{k}_{2}+\mathrm{k}_{3}+2 \mathrm{k}_{4}<1$ such that (2.3) is satisfied. Then $\mathrm{T}$ has a unique fixed point in $\mathrm{X}$.

Proof. From Remark 2.4 (iii), we get that $\mathrm{T}$ is a generalized JS-quasi-contraction with $\lambda=k_{1}+k_{2}+k_{3}+2 k_{4}$. In case of $0<\lambda<1$, by Theorem 2.5, the proof is completed. In case of $\lambda=0$, by (2.1) we have

$$
\psi\left(\operatorname{sp}_{\mathrm{b}}(T x, T y)\right) \leqslant \psi\left(M_{s}(x, y)\right)^{0}=1 \quad \text { for all } x, y \in X
$$

Further, by $(\Psi 1)$ we deduce that $p_{b}(T x, T y)=0$ for all $x, y \in X$. Thus, for $y=T x$, we have $p_{b}(T x, T(T x))=$ 0 . It follows that $y=T x$ is a fixed point of $T$. Let $z$ be another fixed point of $T$. Then

$$
p_{\mathrm{b}}(y, z)=p_{\mathrm{b}}(T y, T z)=0 .
$$

Therefore, $y=z$ and so $T$ has a unique fixed point.

Corollary 2.8. Let $\left(\mathrm{X}, \mathrm{p}_{\mathrm{b}}\right)$ be a $\mathrm{p}_{\mathrm{b}}$-complete partial b-metric space with the coefficient $\mathrm{s} \geqslant 1$ and $\mathrm{T}: \mathrm{X} \rightarrow \mathrm{X}$ be a $\mathrm{p}_{\mathrm{b}}$-continuous mapping. Assume that there exist $\psi \in \Phi_{2}$ and nonnegative real numbers $\mathrm{k}_{1}, \mathrm{k}_{2}, \mathrm{k}_{3}, \mathrm{k}_{4}$ with $\mathrm{k}_{1}+\mathrm{k}_{2}+\mathrm{k}_{3}+2 \mathrm{k}_{4}<1$ such that (2.2) is satisfied. Then $\mathrm{T}$ has a unique fixed point in $\mathrm{X}$.

Corollary 2.9. Let $\left(\mathrm{X}, \mathrm{p}_{\mathrm{b}}\right)$ be a $\mathrm{p}_{\mathrm{b}}$-complete partial b-metric space with the coefficient $\mathrm{s} \geqslant 1$ and $\mathrm{T}: \mathrm{X} \rightarrow \mathrm{X}$ be a $\mathrm{p}_{\mathrm{b}}$-continuous mapping. Assume that there exist $\psi \in \Phi_{4}$ and nonnegative real numbers $\mathrm{k}_{1}, \mathrm{k}_{2}, \mathrm{k}_{3}, \mathrm{k}_{4}$ with $\mathrm{k}_{1}+\mathrm{k}_{2}+\mathrm{k}_{3}+2 \mathrm{k}_{4}<1$ such that (2.4) is satisfied. Then $\mathrm{T}$ has a unique fixed point in $\mathrm{X}$.

Corollary 2.10. Let $\left(\mathrm{X}, \mathrm{p}_{\mathrm{b}}\right)$ be a $\mathrm{p}_{\mathrm{b}}$-complete partial $\mathrm{b}$-metric space with the coefficient $\mathrm{s} \geqslant 1$, and $\mathrm{T}: \mathrm{X} \rightarrow \mathrm{X}$ be $\mathrm{p}_{\mathrm{b}}$-continuous. Assume that there exist $\mathrm{a}>0$ and nonnegative numbers $\mathrm{k}_{1}, \mathrm{k}_{2}, \mathrm{k}_{3}, \mathrm{k}_{4}$ with $\mathrm{k}_{1}+\mathrm{k}_{2}+\mathrm{k}_{3}+2 \mathrm{k}_{4}<1$ such that

$$
\left(s p_{b}(T x, T y)\right)^{a} \leqslant k_{1} p_{b}(x, y)^{a}+k_{2} p_{b}(x, T x)^{a}+k_{3} p_{b}(y, T y)^{a}+2 k_{4}\left(\frac{p_{b}(x, T y)+p_{b}(y, T x)}{2 s}\right)^{a}
$$

for all $x, y \in X$. Then $T$ has a unique fixed point in $\mathrm{X}$.

Proof. From Example 1.13, we have $\psi(t)=e^{t^{a}} \in \Phi_{3}$, and so (2.3) immediately follows from (2.25). Thus, by Theorem 2.7, $\mathrm{T}$ has a unique fixed point.

Corollary 2.11. Let $\left(\mathrm{X}, \mathrm{p}_{\mathrm{b}}\right)$ be a $\mathrm{p}_{\mathrm{b}}$-complete partial b-metric space with the coefficient $\mathrm{s} \geqslant 1$, and $\mathrm{T}: \mathrm{X} \rightarrow \mathrm{X}$ be $\mathrm{p}_{\mathrm{b}}$-continuous. Assume that there exist nonnegative numbers $\mathrm{k}_{1}, \mathrm{k}_{2}, \mathrm{k}_{3}, \mathrm{k}_{4}$ with $\mathrm{k}_{1}+\mathrm{k}_{2}+\mathrm{k}_{3}+2 \mathrm{k}_{4}<1$ such that

$$
\left(\operatorname{sp}_{b}(T x, T y)\right)^{a} \leqslant k_{1} p_{b}(x, y)^{a}+k_{2} p_{b}(x, T x)^{a}+k_{3} p_{b}(y, T y)^{a}+k_{4}\left(\frac{p_{b}(x, T y)+p_{b}(y, T x)}{s}\right)^{a}
$$

for all $x, y \in X$, where $a=\frac{1}{n}$. Then $T$ has a unique fixed point in $\mathrm{X}$.

Proof. For each $a \in(0,1]$, we obtain that

$$
\left(\frac{p_{b}(x, T y)+p_{b}(y, T x)}{s}\right)^{a} \leqslant 2\left(\frac{p_{b}(x, T y)+p_{b}(y, T x)}{2 s}\right)^{a} .
$$

Then (2.26) implies (2.25). Thus, Corollary 2.11 immediately follows from Corollary 2.10. This implies that $\mathrm{T}$ has a unique fixed point. 


\section{Acknowledgment}

The first author is thankful to the Science Achievement Scholarship of Thailand. Moreover, we would like to express our deep thank to Naresuan University for the support.

\section{References}

[1] I. A. Bakhtin, The contraction mapping principle in almost metric space, (Russian) Functional analysis, Ul'yanovsk. Gos. Ped. Inst., 30 (1989), 26-37. 1

[2] S. Banach, Sur les opérations dans les ensembles abstraits et leur application aux équations intégrales, Fund. Math., 3 (1922), 133-181. 1

[3] S. Czerwik, Contraction mappings in b-metric spaces, Acta Math. Inform. Univ. Ostraviensis, 1 (1993), 5-11. 1

[4] D. Hunwisai, P. Kumam, Fuzzy fixed point theorem for multivalued F-contraction in b-metric spaces, Commun. Math. Appl., 7 (2016), 179-187. 1

[5] N. Hussain, V. Parvaneh, B. Samet, C. Vetro, Some fixed point theorems for generalized contractive mappings in complete metric spaces, Fixed Point Theory Appl., 2015 (2015), 17 pages. 1

[6] Z. L. Li, S. J. Jiang, Fixed point theorems of JS-quasi-contractions, Fixed Point Theory Appl., 2016 (2016), 11 pages. 1, $1.12,1.13,1,1.14,1.15,1.16,1.17,2.4$

[7] S. G. Matthews, Partial metric topology, The New York Academy of Sciences. Ann. N. Y. Acad. Sci., 1994 (1994), 183-197. 1

[8] Z. Mustafa, J. R. Roshan, V. Parvaneh, Z. Kadelburg, Some common fixed point results in ordered partial b-metric spaces, J. Inequal. Appl., 2013 (2013), 26 pages. 1, 1.5, 1.6, 1.7, 1.8, 1.9, 1.10, 1.11

[9] H. Piri, P. Kumam, Fixed point theorems for generalized F-Suzuki-contraction mappings in complete b-metric spaces, Fixed Point Theory Appl., 2016 (2016), 13 pages. 1

[10] J. R. Roshan, V. Parvaneh, Z. Kadelburg, N. Hussain, New fixed point results in b-rectangular metric spaces, Nonlinear Anal. Model. Control, 21 (2016), 614-634. 1

[11] S. Shukla, Partial b-metric spaces and fixed point theorems, Mediterr. J. Math., 11 (2014), 703-711. 1, 1.1, 1.2, 1.3, 1.4

[12] P. Sookprasert, P. Kumam, D. Thongtha, W. Sintunavarat, Extension of almost generalized weakly contractive mappings in rectangular b-metric spaces and fixed point results, Afr. Mat., 28 (2017), 271-278. 1

[13] D. Wardowski, Fixed points of a new type of contractive mappings in complete metric spaces, Fixed Point Theory Appl., 2012 (2012), 6 pages. 1 